\title{
Mainstreaming and superdiversity: Beyond more integration ${ }^{1}$
}

\section{Fran Meissner}

The emergent literature on mainstreaming immigrant integration frequently references the term superdiversity. The diversification of migration is put forward as one rational for implementing measures to support immigrant integration across policy fields and across levels of policy making. Research into superdiversity has successfully increased the recognition and study of the complex webs of multiple differentiations that international migration entails and inscribes in local diversities. Superdiversity offers an alternative to equating migration-related diversity with a multiplicity of putatively cohesive origin or ethnic groups - indeed it helps move beyond category focused approaches to making sense of migration-driven and migrant-led diversity (Meissner 2016; Ye 2016a).

Thinking through a superdiversity lens assists in accounting for contemporary configurations of urban and increasingly also rural population dynamics by going beyond cultural difference as a focal concern. Not directly targeting any putative group and choosing to make migration-related diversity a concern across areas and levels of policy making is promising. As this book documents, in practice it is not an easy feat. In this chapter and against the backdrop of the afore gone empirical work, I ask how else, beyond being a rational for mainstreaming, thinking about superdiversity might add to the presented debates. I primarily advance the argument that a superdiversity lens is uniquely placed to critically examine whether the goal of mainstreaming should be integration.

I start the chapter with a brief introduction to superdiversity. I emphasise that the term is not synonymous with more diversity and that the notion instead challenges presumptions about more diversity requiring more integration work. In a second section I reflect on the conclusions of the book's empirical chapters to highlight a number of fault-lines at odds with seeing mainstreaming integration - the way it is currently implemented - as an adequate response to the emergence of superdiversity. I here come to the conclusion that efforts to mainstream integration rarely respond to ideas about complex interconnections of difference - a central facet of superdiversity. Instead what integration means is left vague and the goal of integrating migrants becomes a maxim and a putatively necessary characteristic of a good post-migration society.

In a third section I discuss why mainstreaming practices may suffer from the murkiness of what integration in superdiverse contexts is or ought to be - it neglects the continued stigma associated to the term and the effectiveness of invoking and measuring integration. I thus shift the discussion's focus to the connection between superdiversity and integration. Should it be a given that the goals of mainstreamed policies are framed in terms of integration? I propose that a superdiversity lens can also challenge us to consider the merits of alternative prerogatives such as what I term convivial

\footnotetext{
1 Pre-Print Chapter published in: Scholten, P.; van Breugel, Ilona (Eds.) (2018): Mainstreaming Integration Governance. New Trends in Migrant Integration Policies in Europe. Basingstoke: Palgrave Macmillan.
} 
disintegration. I briefly explore how this might better suit the way everyday diversity is practiced. I conclude the chapter by summarising the main points to highlight the multiple ways in which linking superdiversity with mainstreaming practices can go beyond thinking about more diversity needing more integration.

\section{Superdiversity terminological clarifications}

In this book superdiversity is primarily used to describe 'a context of increasing diversification' (Scholten \& van Breugel, Chapter 1, p. TBD). In my previous work I have delineated three main ways of using superdiversity in applied research. One, as a way to critically chose sets of variables and focal aspects included in investigations. These have to go beyond commonly used categories of migrants. Two, superdiversity as a context in which those variables are at play and finally superdiversity as a malleable social scientific concept that can account for less static conceptions of migration-related diversity (Meissner 2015). Vertovec (2016) has recently expanded and updated this survey of uses and amongst others adds that a superdiversity lens compels innovative thinking about 'the social organisation of difference'. Keeping those multiple applications of the term in mind, it is useful to consider what a diversification of diversity entails, if it is thought about through a superdiversity lens (cf. Vertovec 2015b).

Assertions of increasing diversification often leave implicit what it is that is increased and how. A very simplistic rational for mainstreaming integration might be that there is more migration and thus more diversity and that this in turn also requires more integration work. This simple link however should be avoided as it is at odds with the themes and research challenges superdiversity research points to. At a global level Czika and de Haas (2014) point out that the world has not become more migratory since the 1960's. Instead migration has concentrated with people moving from more places to fewer destinations. As a result, in the European context, an increasing number of cities are inching their way to becoming minority majority cities, a process that has been noted both for larger cities and smaller urban municipalities. At the same time there are many urban centres that have seen an increase in their share of foreign born, but that remain far from becoming majority minority cities. Local diversification trends are variable and to be a useful concept superdiversity has to account for this.

In many national statistics the number of foreign born residents and their offspring has increased over that past decades although often not with the same magnitude as reported from different city contexts. The introduction of the term superdiversity was motivated by those empirical shifts (Vertovec 2007). However, the analytical focus of the term is on changing and complex patterns rather than on continuously increasing levels of diversity. A diversification of origins and an increase in the count of resident migrants, went hand in hand with other stratifications of migrant populations. One superdiversity thesis, subject to empirical verification, is that the latter altered the dynamics of diversity. Central factors include shifting legal provisions directed at migrants, different settlement and moving on patterns, demographic differences in migrant cohorts and how those cohorts engage differently in the labour market, in local social networks and in transnational networks which all link ever more variegated physically distant and close localities. With its focus on the interplay of board and detailed aspects of migration-related differentiations, superdiversity research is often 
concerned with processes through which migration related differences become habitual in everyday socialites (Wise and Velayutham 2009; Vertovec 2015a; Wessendorf 2014).

Superdiversity is not only a useful lens to examine contexts that have experienced exceptional increases in the numbers of foreign born. Whether there are moderate levels or a lot of new migration, superdiversity highlights the notable entanglement of many differentiations that both constrain and provide opportunities for migrants to participate in local social, economic and political structures. As a concept the notion is also useful to consider the social organisation of difference in contexts of moderate or longstanding diversities. Comparative approaches expose how international migration is part of multiple registers of social, cultural and regulatory complexity. Complexity the way it is used in this chapter is about considering more variables but it is not about a larger taxonomic dictionary of diversity, or about counting categories. Instead complexities considered are about the dynamic ways in which often less category focused differentiations - such as those deriving from the interplay between the restrictiveness of immigration rules and movement dynamics - can be thought about as being both co-dependent and as having an accumulated history in contemporary configurations of diversity. This history derives from consecutive changes in how migration and the possible ways through which migration alters social settings gained situational social relevance (Mitchell 1987). It is in considering the simultaneity of multiple differentiations that we get to the heart of superdiversity research.

Defining and talking about superdiversity entails paying attention to complexities in contexts where the sum of differences cannot explain the social dynamics that international migration entails. It is often a fear of small numbers that is framed in terms of large threats and heightened levels of diversity (Appadurai 2006) - so long as this continues difference will also continue to be eyed as disruptive and socially destabilising - as a threat to integration. Yet at points more diversity may entail less antagonistic differences than if relatively clear and contested cleavages dominate in social settings (Brubaker 2008). Considering multidimensional differentiations poses new challenges for addressing and understanding the implications of international migration in local contexts. How those interconnections and their appropriation by migrants produce sometimes unexpected and hard to predict feedback-loops is important for changes in how diversity is perceived and how it is dealt with (Blommaert 2013). It has been noted how remarkably well cities work despite their evident accumulation of difference (Magnusson 2011).

More migrants and categories applied to those migrants is a clear implication of the emergence of superdiversity, but it does not constitute what is at stake in thinking about the term. Considering the multidimensionality of diversifications and how those differentiations co-evolve and change over time is closer to what superdiversity can conceptually capture and add to debates (Meissner 2016) - thus if superdiversity is used as a rational for mainstreaming policies it is important to ask whether those complexities are considered in innovating approaches for dealing with the implications of international migration.

Importantly superdiversity was "proposed as a "summary term" to encapsulate a range of [...] changing variables surrounding migration patterns - and, significantly, their interlinkages - which amount to a recognition of complexities that supersede previous patterns and perceptions of migration-driven diversity' (Meissner and Vertovec 2015, 
542, emphasis added). With reference to changing approaches to governing diversity, superdiversity thought about in this way - more as a concept than as a context - makes it difficult to consider policy shifts as responding to superdiversity. In fact, the very changes in policies discussed in the empirical chapters of this book directly impact on the complexities of superdiversity. Mainstreaming integration and thereby implementing sets of policy tools more broadly and at multiple levels of government and through new governance structures, is itself a driver of superdiversity. At the same time following this definition, it is a valid and important question to ask, whether changed perceptions of diversity altered strategies for addressing the implications of migration and in extension whether those changes are passable. The book's empirical chapters offer insights here and highlight a number of fault-lines at odds with seeing mainstreaming integration - the way it is currently implemented - as an adequate response to the emergence of superdiversity.

\section{Superdiversity and its link to mainstreaming integration - reflecting on empirical chapters}

How diversity is perceived and imagined (Vertovec 2012) is of particular importance for integration policies which arguably, like migration policies, have to satisfy related and sometimes contradictory standards of legitimacy (Boswell 2007; Jong 2015). As we have just noted, superdiversity research aims to shift ideas about diversity away from thinking about more diversity towards thinking about the complexities of diversity. Mainstreaming integration efforts involves changes across different levels of government (cf. Scholten \& van Breugel, Chapter 1) and if superdiversity talk was a rational for mainstreaming integration, it is reasonable to assume that there has to be some recognition of those complexities also across levels of policy making. There is little evidence that this is the case. The empirical work in this book shows instead that we find a clear scalar shift in how much importance can be attributed to the recognition of superdiversity in making the implications of migration a broad policy concern and shifting who or what is targeted by policy initiatives.

At the urban level ideas about (super)diversity have been used to justify and implement mainstreamed approaches to immigrant integration, bringing on board more stakeholders and a more varied portfolio of policy areas (cf. Jóźwiak et Al., Chapter 3; Jensen et Al., Chapter 4). At the same time similar trends at the national level are not framed in terms of the complexities of diversity - instead here a clear shift towards generic often socio-economically focused policy concerns are found to be of increasing importance. Justifications for generic policy frames at the national level are promoted by pointing to austerity and cost-effectiveness. As Helen McCarthy and colleagues (Chapter 5) show, at the EU-level the commitment to using available instruments to promote mainstreaming tools has been limited. Migration and its implications remains a relevant topic at this level, however little in the analysis of Chapter 5 suggests that this is because of the complexities of migration-driven diversity. Pressures to facilitate sufficient adaptability of policy tools is paramount to ensure that implementation in different national contexts and across different policy fields is made possible at all.

The evident hierarchy of importance attributed to superdiversity is not surprising, as Jensen et Al. point out in their analysis: "the city [...] constitutes the coalface of integration where policy frames confront the lived reality of an increasingly diverse population" (Chapter 4, p. TBD). Entanglements of multiple migration-related 
differentiations noted in local contexts disappear in the abstractions of higher-level frameworks. Whether mainstreaming happens in response to the recognition of superdiversity would thus necessarily depend on how close those developing and implementing efforts are to the practical needs that those integration efforts are supposed to address. The chapter by Gidley and colleagues highlighting the crucial role of street-level bureaucrats in implementing mainstreamed policies, offers a good example to highlight the complexities that these actors can and have to accommodate. It is clearly shown that many street-level bureaucrats by necessity cannot disregard the co-relevance of multiple registers of diversity (social diversity, sexual diversity etc.) which likely also involves recognising intricacies within those registers (however also see: Boccagni, 2014). The alluded to hierarchy has the interesting side effect that generic policy frames developed at the national level end up having an immigrant integration focus at the local level (cf. Chapter 4). Considering the types of initiatives described by Jensen et Al. as well as by Jóźwiak et Al. in reviewing how mainstreaming is evident in city contexts, it is important to caution that even if policy approaches are responsive to ideas about altered and heightened diversity, this is not always due to a recognition of the multidimensionality of superdiversity. Regardless of whether diversity is presented as an opportunity to be harnessed or as a challenge that needs to be addressed, central concerns often remain with questions of multi-ethnicity rather than with incorporating additional stratifications of difference. Efforts in multiple European cities described by Jensen show that mainstreaming in local contexts while not targeting any specific origin group, often remains based on the idea that the disintegrative potential of international migration is caused by insufficient contact and understanding between people of different origin groups (cf. Schönwälder 2016). Where migrants are from and ethno-cultural differences remain central in community cohesion and intercultural approaches even if the debates are shifted away from directly targeting specific origin groups.

Ethnic and cultural differences play an important part in understanding and making sense of post-migration societies - and superdiverse contexts are often marked by the everydayness of this type of diversity (Wessendorf 2014). A recognition of the simultaneous stratifications along other migration-related differentiations however are rarely subject of relevant policies. One example that serves to support this is the fact that few city governments are aware of, or actively seek to understand, the spatial distribution of migrants who moved through different immigration channels. This is surprising given the connection between legal status and the socio-economic outcomes of migrants (Söhn 2013). Recent increases in refugee migrations and imminent questions about where in cities new residents will find more sustainable housing, have increased sensitivities in this area (Bolzoni, Gargiulo, and Manocchi 2015). To date these mostly fail to address how refugee migrations together with other migrations add to multiple speeds of change in local diversity configurations and in how diversity is differently experienced and conflict prone in those uniquely configured contexts (for two exceptions see: Phillimore 2013; Biehl 2014).

What types of policies then are considered as examples of mainstreaming integration? The Polish and Spanish comparison representing the empirical case of mainstreaming in new-migration contexts (Chapter 3 ) presents examples where practices are changed in light of heightened diversity but not necessarily in response to superdiversity. Observed adaptations in approaches towards migrant integration and how more actors, 
particularly NGOs, take on mainstreamed integration responsibilities exclusively respond to the presence of more migrants and changes in ethnic, cultural and linguistic diversity. The authors show that while those changed approaches to dealing with the implications of international migration can be described as 'mainstreaming by accident', they also show, in analysing the Polish case, that this may lead to exclusionary practices as particular migrants, such as seasonal workers are not targeted by the described initiatives. This reflects that short term but also intra-EU migrants are often not considered as part of the integration paradigm (Collet 2013). Which is why some advocate that to more fully take advantage of mainstreaming integration concerns, it is necessary to pay attention to 'mobility proofing' and 'diversity proofing' policies (Benton, McCarthy, and Collet 2015).

To be clear, addressing questions about language competences especially in school contexts is important - empirical work suggests that language acquisition is highly relevant for navigating destination contexts (e.g. Hoehne and Michalowski 2016). The example of language support used in the Polish case study is however useful to explain why there is a mismatch between responding to more immigration and responding to superdiversity. What is mainstreamed in practice - the acquisition of the host-country's language and ideas about mono- and bi-lingualism - disregards and maybe even discounts the increasing importance of polylanguaging and how degrees of fluency and situational mobilisation and creolisation of language have strong integrative and simultaneously disintegrative potential. A rapidly growing literature on linguistic superdiversity would certainly point us in this direction (Arnaut et al. 2016; Silverstein 2015; Hogan-Brun 2012). Those tendencies however may simply be outside of the reach of clear and easy to explain policy interventions that can be provided by scarcely funded actors (Boccagni 2014). In thinking about the transformation of generic policy frames in terms of integration it is a non-negligible risk that what is mainstreamed are tools that were developed with older ideas about dealing with difference in mind. These often respond only to smoothing over singular differences rather than engaging with the corelevance of multiple and intricately linked differentiations.

It is thus not entirely clear whether presented practices of mainstreaming integration do respond to a need for whole society approaches, at least not, if we presume that addressing everyone also has to be sensitive to the everyday complexities of diversity. This is also relevant for discussing the argument that to mainstream integration policies it is necessary to pay attention to the 'dilemma of recognition' which was introduced in the first chapter of this book. Doing so in theory demands that mainstreaming entails a vigilant attention to both more generic as well as (non-group) targeted approaches. We can note that efforts described as building on this prerogative are not necessarily successful. With the presented empirical examples, the interconnectedness of multiple differentiations and how they play out in specific contexts appears poorly addressed in making decisions about when, who or what to target. Simone and colleagues (Chapter 2) show that shifting policies to area or needs based targets is not in and of itself a solid strategy to counter pre-existing stigma and structural barriers faced by different migrants. In terms of superdiversity the relevant question might be in how far mainstreamed and devolved policy approaches can be successful if other policies push exclusionary agendas (Gebhardt 2015). 
Area based targeting is not performed in a policy vacuum and approaches that result in proxy-targeting putative groups are likely to not respond to the complexities of superdiversity. As the empirical analysis indicates, a lack of sensitivity for how policy is calibrated risks developing tools that poorly benefit anyone. Such practices carry the added danger of further reducing openness towards needed redistributive efforts, which are linked to attitudes towards migration in general (Dancygier and Donnelly 2013; Bauböck and Scholten 2016). This would reinforce the interlinkages of differentiations and how migrants contribute to social change and why I suggested that considering mainstreaming as a driver of superdiversity may be more useful than to see superdiversity as a rational for mainstreaming. The French case offers the most alarming example of why cautiousness about the effectiveness of shifting from ethnic groups to other putative categories via proxy targets is in order (Bozec and Simon 2014).

Needs based proxies, face similar difficulties, as forecasting where policies have to steer their focus requires high levels of flexibility that may still not bridge the gap between experienced and presumed needs (Phillimore 2015a). Changes in patterns of diversity often result in previously not considered scenarios - uncertainty is a core element of complex social configurations. It is this uncertainty that ideally needs to become part of mainstreaming efforts if they are to adequately respond to superdiversity. Based on the empirical materials it is not entirely clear if this is feasible or if the needed flexibility poses new and different challenges for dealing with diversity. There are evident difficulties in devising policies that are general enough to work across levels of government and areas of policy making but that at the same time can respond to the specificities of superdiverse contexts. Further, proxy approaches expose the importance of highlighting that anti-discrimination measures and measures designed to foster equality and support in emergent and variegated arrival structures, do not always sit easily together under the umbrella term integration (Bozec and Simon 2014). The danger of dilution of problems is then another non-negligible issue.

Beyond these concerns what is interesting in reviewing the researched policy shifts is that at each level considered there appears to be consensus that if there is something that needs to be done in response to international migration and heightened levels of diversity, it has to be integration. This suggests that integration as a goal has become a maxim, a leitmotiv, in what needs to be done to counter the inequities migration entails and to foster a good postmigration society. Some - but certainly not all - of the migration-linked differentiations that a superdiversity lens points to are subject to and product of policy tools framed in terms of migrant integration (cf. MIPEX). The link between superdiversity and integration debates is thus not surprising - yet given the observations that mainstreaming in practice is so far not necessarily an adequate response to dynamically changing configurations of diversity, it is important to question whether those dynamics can be made compatible with the far from unproblematic notion of integration.

\section{Integration as a maxim?}

As Scholten and van Breugel note in their introduction to this book, there have been shifts in how integration policies are framed and implemented. Not least as multicultural approaches have widely fallen out of favour (however see: Banting and Kymlicka 2013) 
and ideas about assimilation have proven to be too one sided (Crul 2016). A turn towards new understandings of integration and what it should entail (cf. Gidley 2012) offers considerable extensions to earlier more rigid ideas that saw integration responsibilities to rest exclusively with non-nationals. However, as the example of mainstreaming integration at the EU level shows - what is mainstreamed may purposively be left open for interpretation in different national and local contexts. Migrant integration even if dispersed through multiple levels of policy making is subject to different policy frames that are applied in local contexts (Caponio, Jubany Baucells, and Güell 2015). This vagueness is relevant for what types of policy interventions are thought of as mainstreaming integration and which goals they should achieve in light of altered perceptions about diversity.

As I suggested at the end of the last section, integration stands somewhat as a maxim in many debates which makes it prone to the dilution of policy priorities criticised at various points in this book. Particularly in the popular debate it is common that perceived or actual increases in migration go hand in hand with debates about how best to integrate new migrants. Here integration stands as a goal that if reached is the beacon of a good postmigration society. This preoccupation with integration can be explained by considering how previous strategies for dealing with new migrants often precluded meaningful participation and resulted in sometimes devastating differences that disproportionally left many (but by no means all) non-nationals in socially and economically disadvantaged positions. Emphasising integration, both of settled and new or short-term migrants, then emphasises predictability by addressing and not repeating the same mistakes. That some of the inequities pointed to in calling for more integration may already be embedded in other policy realms - particularly those of regulating migration - too easily disappears from debates if a unified goal of integration dominates agendas.

Integration as a goal and maxim is certainly not equivalent with the many ways of thinking about what challenges and dynamic changes in social configurations international migration entails. Integration is then seen as a process with many neglected dimensions (Catney, Finney, and Twigg 2011) or as having to be expanded beyond policies targeting people directly or by proxy, to embedding integration by generating change in institutions charged with mainstreamed policy interventions (Phillimore 2015b; Benton, McCarthy, and Collet 2015). The latter efforts, which have the most promise for substantially altering how integration 'is done' (also compare Chapter 7), however remain mostly the exception rather than the rule. Instead ideas about integration are often built on a rhetoric of a two-way processes in which 'the degree of change is almost always unequal, much greater on the immigrant side' (Alba and Foner 2016, 7).

In light of superdiversity this highlights at least two problems. First, integration as a goal perpetuates the reproduction of an image of society where some are thought about as needing to be integrated and others as doing the integrating (Schinkel 2013). It is not surprising that this unhelpfully stirs animosities, both amongst those who never feel integrated regardless of the efforts invested and for those who do feel that they have reached the integration threshold but who neglect that the circumstances and contexts of, for instance, learning the language or participating in the labour market are vastly different for different migrants. The integration dichotomy has divisive characteristics. 
Secondly but relatedly the goal of integration is difficult to align with uncertainties about how the complex interconnections of difference play out in superdiverse contexts. As I noted integration debates tend to be driven by suggesting certainties and the ability to control the implications of international migration in local and supra-local settings. Thinking about superdiversity however is not least about presuming that different contexts subject to similar policy interventions can still diverge in their outcomes as often a condition of 'ceteris paribus' - of all else being equal, cannot account for the local complexities of diversity. Complexity is not least about an inability to trace initial conditions. By implementing integration as a maxim it becomes possible to disregard this very central aspect of complexity which consequently also does not find recognition in the precision of policy goals - rendering them virtually unchallengeable even if their content is relatively unclear.

With those two concerns in mind we may ask whether mainstreaming as a strategy for mobility and diversity proofing policies should be framed in terms of integration at all? Can we be as bold as to say that thinking about mainstreaming in light of superdiversity challenges us to consider alternatives? Should integration be a beacon of what identifies a good postmigration society or is a degree of disintegration permissible - maybe even desirable? Let us think about the example of mobility proofing services and 'adapting to the realities of high population turn-over' (Benton, McCarthy, and Collet 2015, 10). Strictly speaking this is at odds with integration as a maxim because relevant socialites are re-configured constantly. This arguably means that what was there before is, to a degree, disintegrated and reassembled constantly and that this happens in light of the multidimensional differentiations that are emblematic of superdiverse contexts. Even if those contexts can be marked by a familiarity with difference, where at times new strangers are perceived as familiar strangers (Ye 2016b), it is clear that high mobility always entails at least minute changes which make it difficult to clearly define when and how integration as a goal is reached to everyone's satisfaction.

Measuring integration by the presence or absence of certain policies may say something about intentions but not least because of the multiscale adaptations of policies it does not necessarily say much about contextual outcomes. Processes of disintegration do not have to go hand in hand with the perpetuation of inequities or with conflict prone social settings - indeed disintegration may provide the disruptive spaces needed to find convivial solutions and define inclusive goals. If what was there before is reconfigured constantly and sometimes in bursts, this may also lead to what I here term 'convivial disintegration'. Considering research into superdiversity with a focus on when diversity works we will note that this is by no means a rare occurrence (e.g.Amin; Wise and Velayutham 2009; Wessendorf 2014).

The idea of conviviality is frequently emphasised in the literature that alludes to superdiversity (e.g.Nowicka and Vertovec 2014; Wise and Noble 2016; Padilla, Azevedo, and Olmos-Alcaraz 2015). Whilst often linked to the writings of Gilroy (2009) Wise and Nobel $(2016,423)$ have recently suggested that conviviality 'is part of an older and broader concern with the ongoing question of how communities/ cultures/ societies/ nations "stick together"'. While they argue that thinking about conviviality moves concern over cultural difference into the centre of analysis (Wise and Noble 2016, 424) - I would suggest that from a superdiversity perspective it is precisely the co-relevance of cultural aspects and other social, economic and regulatory differences and 
importantly their simultaneity, which is moved into focus and highlights complexities in contexts of diversified diversity (Hannerz 1992). Conviviality is no longer thought of as a concept that can only account for positive encounters but in its multiple uses is giving room to conflictual negotiations of difference and tensions that may persist or ebb and flow in their intensity (Heil 2015). Some also link the notion to ideas about de-growth and thus a critical appraisal of the objectives of policies more generally (Les Convivialistes 2014). In relation to the analysis in this book those possibilities get to the heart of why non-targeting might not exclusively be what is at stake and why unclear policy goals are perpetuated by an emphasis on integration as a maxim without viable alternatives.

Convivial disintegration is marked by a layering of differences and posits concerns over how, when and where these take on salience. A superdiversity lens may thus - as I already suggested in the introduction - point us towards considering the merits of thinking less about integration as a goal and more about notions such as convivial disintegration. Keeping the omnipresence of calls for integration in mind, finding new ways to define what it is that needs to be mainstreamed seems sensible as it is out of the question that concerns over the implications of international migration have developed to be broadly relevant rather than marginal concerns. Thinking about convivial disintegration allows for incorporating uncertainties and contextual specificities in making the case for a boarder adoption of concerns with those implications - both across levels of policy making and across policy portfolios. From this perspective it may be possible to seek innovation in what it is that is mainstreamed without losing sight of the specificities and tensions in local contexts and without resorting to the dichotomous distinction between integrated and not integrated.

This does not mean losing sight of fostering a good postmigration society but it does leave room for recognising that there is no one size fit all solution - even in light of parallel processes of diversification. It is clear that little is won in replacing one term with a combination of two others and more theorising will be necessary to fully develop the notion of convivial disintegration. Yet in briefly introducing it here, I am proposing it as something else that a superdiversity lens can add to the debates in this book - precisely a reflexiveness about what it is that is being mainstreamed.

\section{Conclusion}

As I discussed in this chapter, beyond equating superdiversity with more diversity and calling for mainstreamed approaches to handle those increases, there are two arguments that in a more nuanced way link a recognition of superdiversity with mainstreaming prerogatives. Firstly, if migration related-diversity is something that increasingly defines social configurations in destination contexts - a thesis often associated with thinking about superdiversity - then clearly approaches are needed that account for the fact the migration-related diversities are relevant for all of society. This tends to be expressed in policy initiatives that for example evoke city-citizenship to bring various local stakeholders to the same table (eg. Amsterdam and Rotterdam two of the UPSTREAM Cities). Secondly, channelling integration efforts by targeting origin groups is no longer viable. This aligns with the post-ethnocentric positioning of superdiversity research. Policy measures that are supposed to avert the presumed socially destabilising effects of migration thus have to be addressed through other foci. 
In the previous sections I first demonstrated why superdiversity is indeed incompatible with ideas about more diversity requiring more integration and secondly explored how those two latter points match mainstreaming integration prerogatives in practice. In doing so I identified some mismatch between mainstreaming integration and thinking about superdiversity. Based on this evaluation, , I thirdly elaborated on why I see the crux of the mismatch in the presumption that what needs to be mainstreamed are integration efforts - at least so long as it is not clear how integration is defined and used an argument that rings in tune with the critically evaluated processes of policy dilution going hand in hand with mainstreaming trends.

If we assume that the continued change and interplay of multiple differentiations - both of which I presented as central to thinking about superdiversity - also inevitably mean social rearrangements that entail some disintegration through the introduction of novelty and newness (Phillimore 2015a) - then, so my final argument went, we should think more about processes of disintegration and in particular consider that everyday diversity may be better served by exploring modes of convivial disintegration. Generally, it seems sensible to promote more openness to finding workable solutions to remove barriers to convivial modes of sociality. In part this may be facilitated by asking what are the interlinked differentiations at stake and to recognise the dual possibility of both the integrating and simultaneously disintegrating potential of most measures applied. The question this raises is whether this presents simply a call for reflexiveness about what is mainstreamed or whether there is more to be learned in thinking convivial disintegration further - I have a hunch that the latter is the case..

\section{References}

Alba, Richard, and Nancy Foner. 2016. "Integration's challenges and opportunities in the Wealthy West." Journal of Ethnic and Migration Studies 42 (1): 3-22. doi:10.1080/1369183X.2015.1083770.

Amin, Ash. "Cities and the ethic of care for the stranger.".

Appadurai, Arjun. 2006. Fear of small numbers: An essay on the geography of anger. Public planet books. Durham: Duke University Press.

Arnaut, Karel, Jan Blommaert, Ben Rampton, and Massimiliano Spotti, eds. 2016. Language and superdiversity. New York: Routledge.

Banting, Keith, and Will Kymlicka. 2013. "Is there really a retreat from multiculturalism policies? New evidence from the multiculturalism policy index." Comp Eur Polit 11 (5): 577-98. doi:10.1057/cep.2013.12.

Bauböck, Rainer, and Peter Scholten. 2016. "Introduction to the special issue: "Solidarity in diverse societies: beyond neoliberal multiculturalism and welfare chauvinism"." CMS 4 (1): 797. doi:10.1186/s40878-016-0025-z.

Benton, Meghan, Helen McCarthy, and Elizabeth Collet. 2015. "Into the Mainstream: Rethinking public services for diverse and mobile populations.". 
Biehl, Kristen S. 2014. "Spatializing diversities, diversifying spaces: Housing experiences and home space perceptions in a migrant hub of Istanbul." Ethnic and Racial Studies 38 (4): 596-607. doi:10.1080/01419870.2015.980293.

Blommaert, Jan. 2013. Ethnography, superdiversity and linguistic landscapes: Chronicles of complexity. Critical Language and Literacy Studies 18. Bristol: Multilingual Matters.

Boccagni, Paolo. 2014. "(Super)diversity and the migration-social work nexus: A new lens on the field of access and inclusion?" Ethnic and Racial Studies 38 (4): 608-20. doi:10.1080/01419870.2015.980291.

Bolzoni, Magda, Enrico Gargiulo, and Michele Manocchi. 2015. "The social consequences of the denied access to housing for refugees in urban settings: The case of Turin, Italy." International Journal of Housing Policy 15 (4): 400-417. doi:10.1080/14616718.2015.1053337.

Boswell, Christina. 2007. "Theorizing Migration Policy: Is There a Third Way?" Int Migration Rev 41 (1): 75-100. doi:10.1111/j.1747-7379.2007.00057.x.

Bozec, Géraldine, and Patrick Simon, eds. 2014. Integration policies in France: Mainstreaming to increase actions towards immigrants or to dilute them into social policies?

Brubaker, Rogers. 2008. Nationalist politics and everyday ethnicity in a Transylvanian town. [Pbk. ed.]. Princeton, N.J. Princeton University Press.

Caponio, Tiziana, Olga Jubany Baucells, and Berta Güell. 2015. "Civic integration policies from below: Accounting for processes of convergence and divergence in four European cities." Ethnic and Racial Studies 39 (5): 878-95. doi:10.1080/01419870.2015.1080379.

Catney, Gemma, Nissa Finney, and Liz Twigg. 2011. "Diversity and the Complexities of Ethnic Integration in the UK: Guest Editors' Introduction." Journal of Intercultural Studies 32 (2): 107-14. doi:10.1080/07256868.2011.547171.

Collet, Elizabeth. 2013. "The integration needs of mobile EU citizens: Impediments and opportunities.".

Crul, Maurice. 2016. "Super-diversity vs. assimilation: How complex diversity in majority-minority cities challenges the assumptions of assimilation." Journal of Ethnic and Migration Studies 42 (1): 54-68. doi:10.1080/1369183X.2015.1061425.

Czaika, Mathias, and Hein de Haas. 2014. "The Globalization of Migration: Has the World Become More Migratory?" Int Migr Rev 48 (2): 283-323. doi:10.1111/imre.12095.

Dancygier, Rafaela M., and Michael J. Donnelly. 2013. "Sectoral Economies, Economic Contexts, and Attitudes toward Immigration." The journal of politics 75 (1). doi:10.1017/S0022381612000849.

Gebhardt, Dirk. 2015. "When the state takes over: Civic integration programmes and the role of cities in immigrant integration." Journal of Ethnic and Migration Studies 42 (5): 742-58. doi:10.1080/1369183X.2015.1111132. 
Gidley, Ben. 2012. "Five principles of integration: policies and inclusion." Accessed September 15, 2016. http://www.compas.ox.ac.uk/2012/five-principles-of-integrationpolicies-and-inclusion/.

Gilroy, Paul. 2009. After empire: Melancholia or convivial culture? Repr. Abingdon: Routledge.

Hannerz, Ulf. 1992. Cultural complexity: Studies in the social organization of meaning. New York, NY: Columbia Univ. Press.

Heil, Tilmann. 2015. "Conviviality: (Re)negotiating minimal consensus." In Routledge international handbook of diversity studies, edited by Steven Vertovec, 317-24. Routledge international handbooks. New York: Routledge.

Hoehne, Jutta, and Ines Michalowski. 2016. “Long-Term Effects of Language Course Timing on Language Acquisition and Social Contacts: Turkish and Moroccan Immigrants in Western Europe." Int Migr Rev 50 (1): 133-62. doi:10.1111/imre.12130.

Hogan-Brun, Gabrielle. 2012. "Language planning in urban spaces." Current Issues in Language Planning 13 (3): 145-47. doi:10.1080/14664208.2012.722378.

Jong, Sara de. 2015. "Converging logics? Managing migration and managing diversity." Journal of Ethnic and Migration Studies 42 (3): 341-58. doi:10.1080/1369183X.2015.1074857.

Les Convivialistes. 2014. Das konvivialistische Manifest: Für eine neue Kunst des Zusammenlebens. Edited by Frank Adloff and Claus Leggewie. X-Texte zu Kultur und Gesellschaft. Bielefeld: Transcript.

Magnusson, Warren. 2011. Politics of urbanism: Seeing like a city. Interventions. London: Taylor \& Francis Routledge.

Meissner, Fran. 2015. "Migration in migration-related diversity? The nexus between superdiversity and migration studies." Ethnic and Racial Studies 38 (4): 556-67. doi:10.1080/01419870.2015.970209.

Meissner, Fran. 2016. Socialising with Diversity: Relational Diversity through a Superdiversity Lens. 1st ed. 2016. Global Diversities. London: Palgrave Macmillan UK.

Meissner, Fran, and Steven Vertovec. 2015. "Comparing super-diversity." Ethnic and Racial Studies 38 (4): 541-55. doi:10.1080/01419870.2015.980295.

Mitchell, J. C. "The situational Perspective." In Mitchell 1987 -Cities, society, 1-33.

Nowicka, M., and S. Vertovec. 2014. "Comparing convivialities: Dreams and realities of living-with-difference." European Journal of Cultural Studies 17 (4): 341-56. doi:10.1177/1367549413510414.

Padilla, Beatriz, Joana Azevedo, and Antonia Olmos-Alcaraz. 2015. "Superdiversity and conviviality: Exploring frameworks for doing ethnography in Southern European intercultural cities." Ethnic and Racial Studies 38 (4): 621-35. doi:10.1080/01419870.2015.980294. 
Phillimore, Jenny. 2013. "Housing, Home and Neighbourhood Renewal in the Era of Superdiversity: Some Lessons from the West Midlands." Housing Studies 28 (5): 682700. doi:10.1080/02673037.2013.758242.

Phillimore, Jenny. 2015a. "Delivering maternity services in an era of superdiversity: The challenges of novelty and newness." Ethnic and Racial Studies 38 (4): 568-82. doi:10.1080/01419870.2015.980288.

Phillimore, Jenny. 2015b. "Embedded Integration and Organisational Change in Housing Providers in the UK." Social Policy \& Society, 1-14. doi:10.1017/S1474746415000639.

Schinkel, Willem. 2013. "The imagination of 'society' in measurements of immigrant integration." Ethnic and Racial Studies $36 \quad$ (7): 1142-61. doi:10.1080/01419870.2013.783709.

Schönwälder, Karen. 2016. Diversity and contact: Immigration and social interaction in German cities. Basingstoke: Palgrave Macmillan.

Silverstein, Michael. 2015. "How language communities intersect: Is "superdiversity" an incremental or transformative condition?" Language \& Communication 44: 7-18.

Söhn, Janina. 2013. "Unequal Welcome and Unequal Life Chances: How the State Shapes Integration Opportunities of Immigrants." Arch. eur. sociol. 54 (02): 295-326. doi:10.1017/S0003975613000155.

Vertovec, Steven. 2007. "Super-diversity and its implications." Ethnic and Racial Studies 30 (6): 1024-54. doi:10.1080/01419870701599465.

Vertovec, Steven. 2012. "'Diversity" and the Social Imaginary." Arch. eur. sociol. 53 (03): 287-312. doi:10.1017/S000397561200015X.

Vertovec, Steven, ed. 2015a. Diversities Old and New. London: Palgrave Macmillan UK. Vertovec, Steven. 2015b. "Introduction: Migration, Cities, Diversities 'Old' and 'New'." In Diversities Old and New, edited by Steven Vertovec, 1-22. London: Palgrave Macmillan UK.

Vertovec, Steven. 2016. "Super-diversity as concept and approach: whence it came, where it's at, and whither it's going." 'Super-Diversity: A Transatlantic Conversation', New York, April 4. http://www.mmg.mpg.de/online-media/onlinelectures/2016/steven-vertovec-mpi-mmg-super-diversity-as-concept-and-approachwhence-it-came-where-its-at-and-whither-its-going/.

Wessendorf, Susanne. 2014. Commonplace diversity: social relations in a super-diverse context: Social relations in a super-diverse context. Global Diversities. Basingstoke: Palgrave Macmillan.

Wise, Amanda, and Greg Noble. 2016. "Convivialities: An Orientation." Journal of Intercultural Studies 37 (5): 423-31. doi:10.1080/07256868.2016.1213786.

Wise, Amanda, and Selvaraj Velayutham. 2009. Everyday multiculturalism. Houndmills, Basingstoke, Hampshire: Palgrave Macmillan. 
Ye, Junjia. 2016a. "Spatialising the politics of coexistence: Gui ju (规矩) in Singapore." Trans Inst Br Geogr 41 (1): 91-103. doi:10.1111/tran.12107.

Ye, Junjia. 2016b. "The ambivalence of familiarity: Understanding breathable diversity through fleeting encounters in Singapore's Jurong West." Area 48 (1): 77-83. doi:10.1111/area.12237. 
Beyond migrant integration.

Mainstreaming as a governance challenge

Peter Scholten and Ilona van Breugel (eds) 
[Bios authors - add]

1. CONCEPTUALIZING MAINSTREAMING IN INTEGRATION GOVERNANCE - PETER SCHOLTEN AND ILONA VAN BREUGEL ERROR! BOOKMARK NOT DEFINED.

Background

Error! Bookmark not defined.

Conceptualising mainstreaming

Error! Bookmark not defined.

Outline of the book

Error! Bookmark not defined.

2. MAINSTREAMING AND REDEFINING THE IMMIGRANT INTEGRATION DEBATE IN OLD MIGRATION COUNTRIES. A CASE STUDY OF FRANCE, THE UNITED KINGDOM AND THE NETHERLANDS - PATRICK SIMON

ERROR! BOOKMARK NOT DEFINED.

3. MAINSTREAMING BY ACCIDENT IN THE NEW-MIGRATION COUNTRIES: THE ROLE OF NGOS IN SPAIN AND POLAND - IGNACY JÓŹWIAK, MARÍA SÁNCHEZ-DOMÍNGUEZ, DANIEL SORANDO

ERROR! BOOKMARK NOT DEFINED.

Introduction

The impact of international migration in Poland and Spain.

Migrant integration policies in Poland and Spain.

The effects of dependency on NGOs for immigrant integration.

Conclusions: mainstreaming happens.
Error! Bookmark not defined. Error! Bookmark not defined. Error! Bookmark not defined. Error! Bookmark not defined. Error! Bookmark not defined.

\section{IMMIGRANT INTEGRATION MAINSTREAMING AT THE CITY LEVEL - OLE JENSEN} ERROR! BOOKMARK NOT DEFINED.

Introduction

Cities and diversity

National and local policy frames

Proxy strategies

Diversity proofing

Conclusion

Bibliography:
Error! Bookmark not defined. Error! Bookmark not defined. Error! Bookmark not defined. Error! Bookmark not defined. Error! Bookmark not defined. Error! Bookmark not defined. Error! Bookmark not defined.

5. IMMIGRANT INTEGRATION MAINSTREAMING AT THE EU LEVEL - ELIZABETH COLLETT, HELEN MCCARTHY AND MEGHAN BENTON ERROR! BOOKMARK NOT DEFINED. Introduction Error! Bookmark not defined. 
Mainstreaming Integration Policy across the European Commission

Tools to promote mainstreaming

Remaining Challenges

The Impact of the Refugee Crisis

Conclusion

Bibliography
Error! Bookmark not defined.

Error! Bookmark not defined.

Error! Bookmark not defined.

Error! Bookmark not defined.

Error! Bookmark not defined.

Error! Bookmark not defined.

6. THE POLITICS OF MAINSTREAMING: THE RATIONALE BEHIND MAINSTREAMING ILONA VAN BREUGEL AND PETER SCHOLTEN ERROR! BOOKMARK NOT DEFINED.

Introduction

Searching for the rationale behind mainstreaming

Comparing types of mainstreaming

Comparing mainstreaming processes

Explaining mainstreaming

Conclusions
Error! Bookmark not defined.

Error! Bookmark not defined.

Error! Bookmark not defined.

Error! Bookmark not defined.

Error! Bookmark not defined.

Error! Bookmark not defined.

7. MAINSTREAMING IN PRACTICE; THE EFFICIENCIES AND DEFICIENCIES OF MAINSTREAMING FOR STREET-LEVEL BUREAUCRATS - BEN GIDLEY, PETER SCHOLTEN AND ILONA VAN BREUGEL ERROR! BOOKMARK NOT DEFINED.

Introduction

Integration governance at the street-bureaucrat level

Methods

Mainstreaming in Education

Mainstreaming in Social cohesion

Neighbourhood policy

Analysis

Conclusions
Error! Bookmark not defined. Error! Bookmark not defined. Error! Bookmark not defined. Error! Bookmark not defined. Error! Bookmark not defined. Error! Bookmark not defined. Error! Bookmark not defined. Error! Bookmark not defined.

\section{THE DILUTION OF THE ULTIMATE GOAL? LESSONS FROM GENDER MAINSTREAMING \\ - PETRA MEIER \\ ERROR! BOOKMARK NOT DEFINED.}

The prerequisites for gender mainstreaming and for mainstreaming integration policies

Error! Bookmark not defined. 
The assumption of social change in gender mainstreaming and what it says about integration policies Error! Bookmark not defined.

Mainstreaming gender equality or integration and more emphasis on prerequisites Error! Bookmark not defined.

The understanding of gender or where gender mainstreaming and mainstreaming integration policies finally meet

Error! Bookmark not defined.

10. ANTI-DISCRIMINATION POLICIES IN THE MAINSTREAM - PATRICK SIMON ERROR! BOOKMARK NOT DEFINED.

11. MAINSTREAMING INTERCULTURALISM IN CITIES: POLICY PARADIGM CHANGE AND FORMATION - RICHARD ZAPATA-BARRERO ERROR! BOOKMARK NOT DEFINED.

Introduction: the Intercultural debate acquis: examining mainstreaming and interculturalism magnetism.

Error! Bookmark not defined.

Framing the policy paradigm change: Beating three multicultural idols Error! Bookmark not defined.

MIc policy paradigm main philosophy: problem-solving approach and the pragmatic turn on diversity management

Error! Bookmark not defined.

MIc is a more appropriate framework for dealing with the complexity of current super-diverse societies and transnational minds Error! Bookmark not defined.

Conclusions: the advantages of MIc Error! Bookmark not defined.

12. MAINSTREAMING AND SUPERDIVERSITY: BEYOND MORE INTEGRATION- FRAN MEISSNER [FIRST DRAFT]

Superdiversity terminological clarifications

Superdiversity and its link to mainstreaming integration - reflecting on empirical chapters

Conclusion

14. CONCLUSIONS - PETER SCHOLTEN AND ILONA VAN BREUGEL ERROR! BOOKMARK NOT DEFINED.

EPILOGUE; MAINSTREAMING AND SOCIAL CLASSIFICATION - DVORA YANOW 
